\title{
"STANDARD BONE"
}

\section{A DESCRIPTION OF RADIOGRAPHIC TECHNIQUE}

\author{
(Being an Appendix to the Article on Page 1 of the March issue)
}

BY

\section{GEORGE D. STEVEN}

The following is a description of the "Standard Bone" now included in the " standardized radiographs of the hands" of all patients at the Royal National Hospital for Rheumatic Diseases, Bath.

Chiefly because this bone is so commonly involved in rheumatoid arthritis, the bone chosen is a second metacarpal of a normal adult. After treatment for defatting in the laboratory, tests were made with the bone embedded in paraffin wax of appropriate thickness-wax being generally considered to have an absorptive effect on $x$ rays equivalent to the soft tissues of the body. These tests, however, showed quite clearly that the absorptive effect of the paraffin wax was less than the tissues, with the result that the standard bone failed in its purpose as a control to demonstrate the presence of early osteoporosis in rheumatoid arthritis. Further tests were made with a mixture which is emptoyed in making radium moulds. This consists of paraffin wax ( 5 parts), beeswax ( 5 parts) and fine sawdust ( 1 part by weight). The results obtained with this medium were satisfactory. Radiographs of the standard bone are shown in Fig. 1, page 185. The bone is contained in a thin cardboard box which is $3 \mathrm{~cm}$. deep at the knuckle end, and $4 \mathrm{~cm}$. deep at the base or wrist end-corresponding with the measurements of the average adult hand. By acting as a normal control, the standard bone assists in the detection of early osteoporosis. It also serves to confirm any $x$-ray appearance of subsequent progress. In advanced cases it helps to differentiate changes of quiescent rheumatoid arthritis from gout, as the presence of generalized osteoporosis may be a deciding factor when these diseases simulate each other. Fig. 2, page 185, shows a radiograph of the hands of a normal adult with the standard bone in position. 


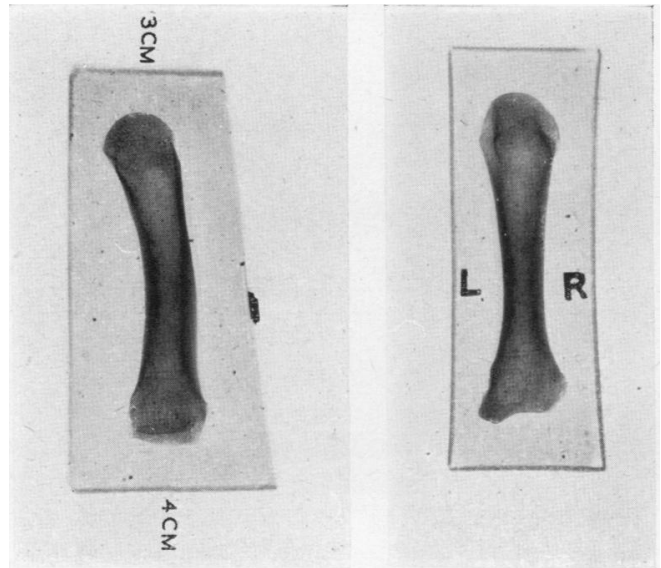

FIG. 1.-Radiographs of the "standard bone" used in conjunction with a "standard technique" for the hands. A second metacarpal bone is shown embedded in a wax mixture which is equivalent in absorptive effect to the soft tissues of the body. The side view shows a thickness of $3 \mathrm{~cm}$. at the knuckle end with $4 \mathrm{~cm}$. at the base or wrist end.

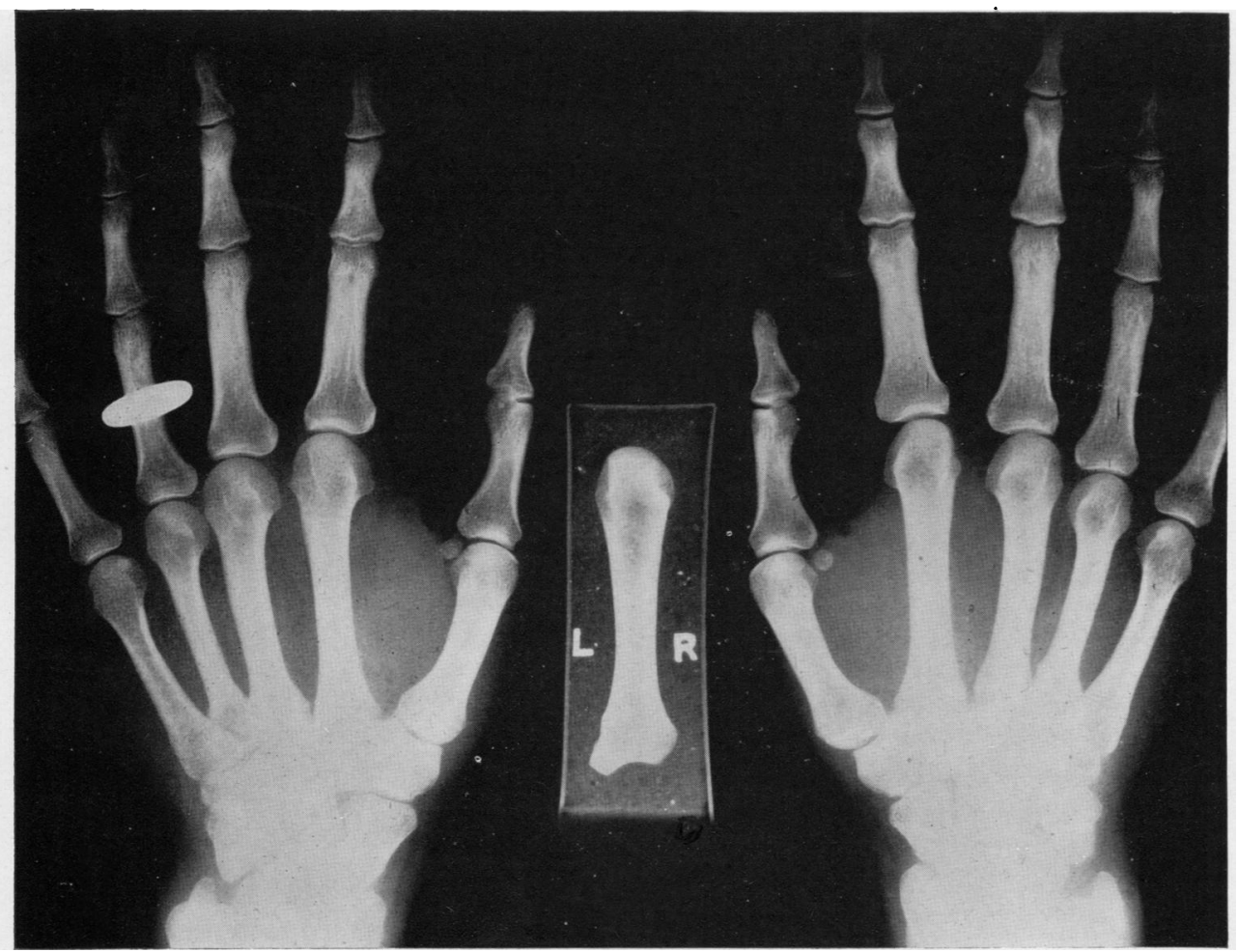

FiG. 2.-Radiograph of the hands of a normal adult. A standardized technique for radiography of the hands is employed, and a standard bone is included to act as a control. 